\title{
Analysis of Different Digital Alternatives as Teaching Tools to Improve the Teaching-Learning Process
}

\author{
Victor Perez-Puyana *(D), Mercedes Jiménez-Rosado (D) and Alberto Romero (iD \\ Department of Chemical Engineering, Faculty of Chemistry, 41012 Seville, Spain; mjimenez42@us.es (M.J.-R.); \\ alromero@us.es (A.R.) \\ * Correspondence: vperez11@us.es
}

\begin{abstract}
Virtual tools are frequently used in education. Among them, the use of virtual laboratories could be an interesting alternative to strengthen the practical concepts of the students, especially in the current paradigm in which the presence of students is often not possible. For this reason, the aim of this study was to analyse the use of different digital tools for the improvement of the teaching process during the COVID-19 pandemic period. To this end, a comparison of the application of different digital alternatives was carried out, evaluating the differences found with previous teaching courses. The results indicate that, although students welcome these activities, they cannot replace face-to-face practices, being considered as a complementary activity.
\end{abstract}

Keywords: virtual reality; online teaching; university teaching; alternative teaching

Citation: Perez-Puyana, V.; Jiménez-Rosado, M.; Romero, A. Analysis of Different Digital Alternatives as Teaching Tools to Improve the Teaching-Learning Process. Knowledge 2021, 1, 75-82 https://doi.org/10.3390/ knowledge1010008

Academic Editor: Jose María Merigo

Received: 20 October 2021

Accepted: 26 November 2021

Published: 3 December 2021

Publisher's Note: MDPI stays neutral with regard to jurisdictional claims in published maps and institutional affiliations.

Copyright: (c) 2021 by the authors. Licensee MDPI, Basel, Switzerland. This article is an open access article distributed under the terms and conditions of the Creative Commons Attribution (CC BY) license (https:// creativecommons.org/licenses/by/ $4.0 /)$.

\section{Introduction}

Currently, there are 83 higher-education institutions (universities and permanent training centres) in Spain. Among these, the vast majority (83.8\%) opt for face-to-face education; thus, virtual or distance alternatives are only found in private centres [1]. However, due to the global pandemic caused by COVID-19, face-to-face teaching has had to be adapted to a virtual paradigm [2]. In this way, the majority of Spanish highereducation centres have adopted a strategy where the theoretical classes are developed virtually. Nevertheless, the centres have been reluctant to adopt practical credits to a virtual modality. This presence is not easy, since most practical credits, especially in the area of science and engineering, are developed in small laboratories. In this way, in order to comply with the maximum capacity and the minimum safety distance between the students, the number of practice groups had to be increased or, which has been more recurrent, the number of practical hours per student had to be reduced in order to be able to carry out the practical lectures without the need to increase the number of working hours of the faculty. However, could this deficit not be alleviated through the use of technological tools?

The use of virtual reality in education has developed since the beginning of the 2000s. Virtual reality is an environment of scenes and objects of real appearance, generated by computer technology, which creates in the user the sensation of being immersed in it [3]. In this way, Escatín (2000) has already evaluated the potential of virtual reality as a material support for teaching [4]. Mendoza (2016) also mentioned the importance of this tool, categorising it as the future of education [5]. Thus, virtual reality has been established in recent years as something common, but surprising in Spanish education, as Aznar Díaz et al. (2018) commented [6]. In this way, the use of technological tools has increased significantly in university education in recent years. In this sense, eight out of ten faculty members claim to use them during their teaching [7]. The most used resources include educational videos. These videos are intended to teach, in an entertaining way, some key concepts of a subject, thus strengthening their understanding. This tool is widely used, as it can be easily made, requiring little specialised material. In this way, it is only necessary to have a video camera and access to one of the unlimited video-editing applications available 
online for free. In addition, they can reach students easily due to the large number of existing broadcast platforms (YouTube, Instagram, TikTok, etc.). Nevertheless, these videos do not allow developing the skills obtained during the practical sessions, since the students cannot interact with the material used [8].

The great advancement of technology has made it possible to obtain other alternative tools that can help the development of these competences electronically. An example of this is the use of virtual reality, which is a simulation of a real environment that creates in the user the sensation of being in it, adding a new dimension to digital learning [9]. Virtual labs are available $24 \mathrm{~h}$ a day and are an easily accessible simulated replica of real labs that allow students to develop practical scientific skills. In this sense, a large number of professionals have opted for the creation of virtual laboratories, where students can practice and acquire the necessary skills from the safety of their home, such as the University of Cordoba (UCo) [10] or the University of Alcalá (UAH) [11]. In fact, there are hundreds of thousands of learning applications, especially in the field of engineering. However, the use of this tool is still limited in Spain, with few virtual laboratories created for socio-sanitary subjects, where it is more complex to carry out virtual experiments.

There are some works that compare the face-to-face and online learnings in different areas. In this way, Watson (2008) and Powell et al. (2015) encourage the use of new technologies to improve students' skills, although always in combination with face-to-face lessons [12,13]. On the other hand, Cannon et al. (2021) highlight the importance of student involvement in virtual teaching, since it is a more autonomous learning than a face-to-face one and, therefore, needs greater involvement and interest in order to work properly [14]. In the same sense, Ganiyu (2021) found that active participation in online lessons is essential to involve students emotionally, behaviourally, and cognitively in this type of methodology, which implies a greater effort on the part of the teacher and the student [15]. In this way, and as Bartley and Golek (2004) point out, online teaching can give benefits compared to face-to-face teaching, since it can reach a large number of students, also reducing the costs of education. However, a great effort must be made to adapt the teaching that until now has been carried out in a face-to-face method to environments where students can learn in the same way, without reducing the skills that they can learn [16].

In this context, the main objective of this work was the evaluation of different digital alternatives to improve the teaching-learning process since there are some situations in which face-to-face teaching is not possible to be carried out. In this sense, our research question is related to which alternative is the most suitable to improve or substitute face-toface teaching when it is not possible to be carried out. This purpose was performed by using virtual reality as a tool for the development of practical skills in the subject of biomaterials, which is taught in the Degree of Materials Engineering (ME) and in the double Degrees of Physics and Materials Engineering and Chemistry and Materials Engineering (PME and QME, respectively) of the University of Seville. In this case, two virtual alternatives were evaluated against the face-to-face practical lectures. In one of them, educational videos were used as a virtual tool to carry out the practical sessions. On the other hand, a virtual lab was used, carrying it out as a game that the students had to solve in order to "escape" from the laboratory. These two tools were evaluated through the marks obtained by the students in the practical part of the subject, comparing them with those obtained in the face-to-face practical lectures. In addition, feedback was obtained through a survey, where the students shared their perspective about the use of virtual tools during the practical section of the subject.

\section{Methodology}

\subsection{Teaching Method}

The main issue of this work is related to the analysis of different virtual alternatives to potentially replace face-to-face lectures. In this context, three different methodologies were carried out, including the use of educational videos or virtual labs instead of face-to-face teaching. Briefly, the students had to attend the practical labs, in the face-to-face case, or 
they had to connect to the Blackboard Collaborate platform (online software) when the practical lectures were carried out online. The methodologies were named: "Face-to-face practical sessions," "Educational videos," and "Virtual lab," and they are described below.

The face-to-face practical lectures were carried out in groups of three students, while the online practical sessions were carried out individually, that is, each of the students individually entered the virtual platform without interacting with the rest. The practical lectures were based on problem-based learning (PBL). In this way, the students had an initial problem that they had to solve in order to conclude the practical lectures. The students had to use an inductive method, where they actively participated, learning from their own deduction to reach the end of the practical session.

This working method was intended to promote certain specific competencies that engineering students should have. Thus, the aim was that the students acquired skills to identify different biomaterials, based on their structure, and to know the techniques of characterisation and analysis of these materials, knowing how to evaluate and select biomaterials according to their applications.

\subsection{Face-to-Face Practical Sessions}

The students had to attend $10 \mathrm{~h}$ of face-to-face practical classes. These practical sections consisted in a first theoretical hour (Figure 1A), where the teacher explained the dynamics to follow in the laboratory and the key concepts to know before starting the practical lectures. Then, the students were given a script (Figure 1B) about the steps to follow in order to obtain the necessary data in the laboratory (Figure 1C), which they had to interpret in order to conclude the practical section.

A

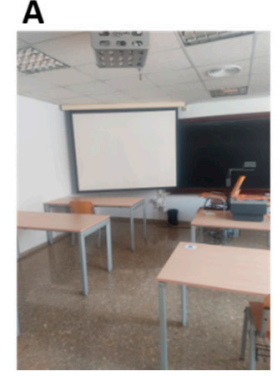

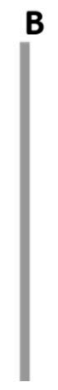
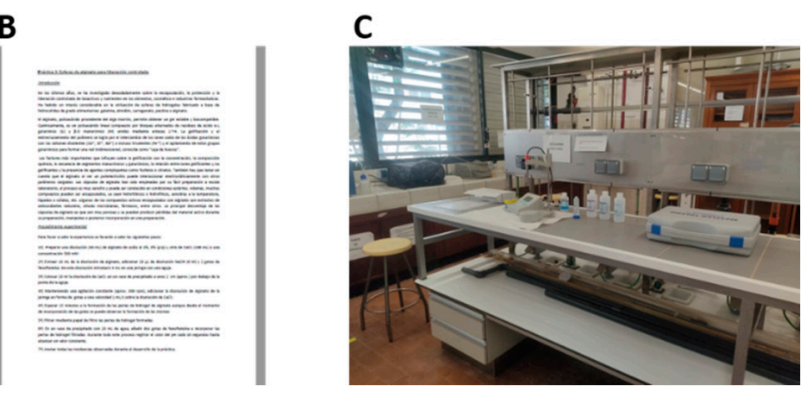

Figure 1. Face-to-face practical lectures. (A) Theoretical classroom. (B) Script. (C) Experimental classroom.

The evaluation of this practical session was carried out from a practice report that the students had to deliver. In this report, they had to explain the initial problem, the steps taken to solve it, and the conclusions drawn. In addition, $10 \%$ of the mark corresponded to the ease observed by the faculty member in the students in the lab work.

\subsection{Educational Videos}

This method consisted in a series of videos (4 videos of about $20 \mathrm{~min}$ ) [17-20] on the practical sessions of the laboratory (Figure 2A). All the videos had the same dynamics: a first theoretical part (Figure 2B), where the fundamentals of the practical session are explained, and a second part, which shows how the experimentation of the practical section is carried out (Figure 2C).

In this case, the students had to watch all the videos and then elaborate a practice report, as in the case of the face-to-face practical lectures, but without carrying out the practical lectures themselves. 
A

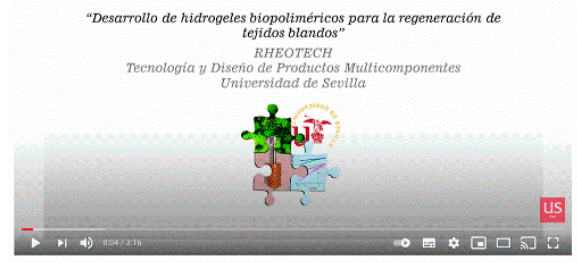

B

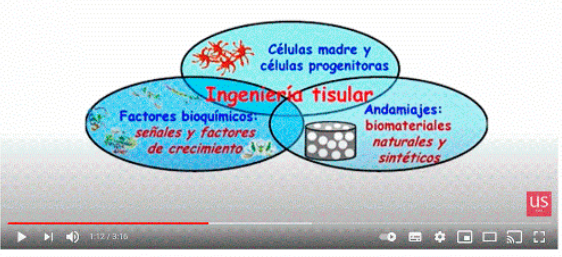

C

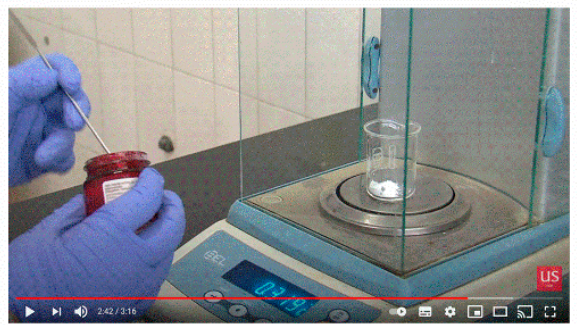

Figure 2. Educational videos. (A) Video cover. (B) Theoretical part. (C) Experimental part.

\subsection{Virtual Lab}

In the case of the virtual lab, a software was created: "EscapeLab: In search of the lost biomaterial" [21]. This software has 7 different routes (Figure 3A), which lead to the identification of different polymeric, metallic, or ceramic biomaterials. Before starting, each student was assigned the routes with which they had to work (each route can be solved in a maximum of $10 \mathrm{~min}$ ). In this software, the students had to guess what biomaterial is in the laboratory, through the properties hidden in each of the rooms (Figure 3B), in order to escape from it.

A

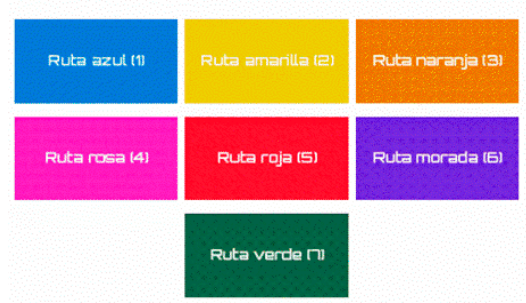

B

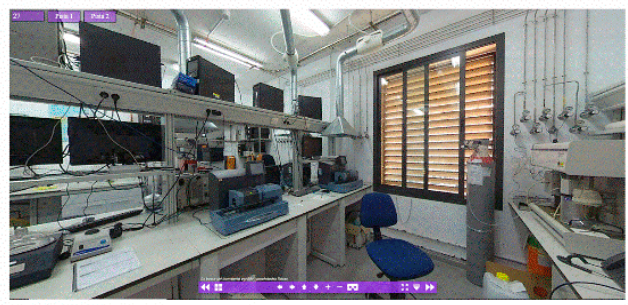

C

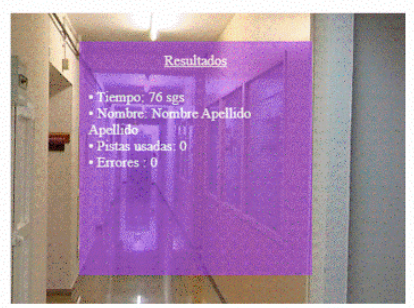

Figure 3. Virtual lab software. (A) Different routes. (B) Physical properties room. (C) Results screen.

Firstly, the necessary instructions were given to the students so that they could operate in the software. Thus, they were explained: (1) how to move around the different rooms (physical properties, microanalysis, microscopy, and X-rays), (2) how to use the equipment, and (3) that they had to go to at least three rooms before being able to solve the practical lecture. It was also explained to them that they had two clues that they could use, although their use penalised the student with time (300 s). On the other hand, incorrect answers also penalised (300 s) and sent the student back to the initial screen, since, without the correct answer, the student could not escape. It is important to mention that each student had to enter his/her name before starting EscapeLab to then record their results. A window appeared with the participant's results record (Figure 3C) when they identified the biomaterial. This screen showed the total time, the clues used, and the mistakes made. These data were used in the evaluation of the student.

\subsection{Analysed Data}

This experience was carried out in the biomaterials subject in three consecutive years, using data from three specialties: the Degree of Materials Engineering (IM, second semester of the third year), the double Degree of Physics and Materials Engineering (FIM), and the double Degree of Chemistry and Materials Engineering (QIM, both in the second semester of the fifth year) of the University of Seville. In this way, the differences found in the three types of methodologies used were evaluated. In addition, the results were segregated by course, specialty, and gender to study their influence on the use of each of these methodologies. In order to compare these variables, the marks of the practical section obtained by the students were taken into account. 


\subsection{Satisfaction Surveys}

Finally, the students were asked to evaluate their experience in the practical sessions conducted to find out what they thought of the proposed alternatives to the face-to-face practical lectures. To this end, they rated from 1 (strongly disagree) to 5 (strongly agree) the statements listed in Table 1.

Table 1. Questions used in satisfaction surveys.

\begin{tabular}{cc}
\hline Reference & Question \\
\hline 1 & This activity was interesting and motivating for me \\
2 & This activity helped me to consolidate the knowledge put into practice during the academic year \\
3 & Online activities could replace face-to-face practical lectures \\
5 & I would do online activities if they were repeated in future subjects \\
In general, I am very satisfied with the idea and the course of the activity
\end{tabular}

\subsection{Statistical Analysis}

All the results were presented as mean values and their standard deviations. These values were calculated using the statistical package Excel Office 365 (Microsoft, Redmond, WA, USA). The significance was estimated with a $95 \%$ confidence $(p<0.05)$.

\section{Results and Discussion}

\subsection{Analysed Data}

Table 2 shows the average marks of the students obtained in the different experiences. As can be seen, no significant differences were found between the global classifications obtained by each of the experiences. In this way, the change in the methodology did not affect the final mark of the students, which can be adapted in all cases.

Table 2. Marks obtained in practical sessions.

\begin{tabular}{ccccccc}
\hline Experience & \multicolumn{3}{c}{ Degree } & \multicolumn{2}{c}{ Gender } & \multicolumn{2}{c}{ Global } \\
& ME & PME & CME & Male & Female \\
\hline Face-to-face practical lectures & $6.9 \pm 1.1$ & $8.5 \pm 0.6$ & $8.2 \pm 0.7$ & $7.5 \pm 1.2$ & $8.3 \pm 0.6$ & $7.7 \pm 1.1$ \\
Educational videos & $7.1 \pm 1.9$ & $8.3 \pm 0.9$ & $8.2 \pm 0.7$ & $7.6 \pm 1.5$ & $8.1 \pm 1.5$ & $7.7 \pm 1.5$ \\
Virtual lab & $7.3 \pm 1.4$ & $9.3 \pm 0.8$ & $9.2 \pm 0.8$ & $8.1 \pm 1.6$ & $8.7 \pm 1.2$ & $8.3 \pm 1.5$ \\
\hline
\end{tabular}

Regarding the segmentations, an increase was observed in the marks obtained by the students of the double degrees with respect to those of the simple degree, although without significant differences, except in the case of the face-to-face practical lectures. This upward trend could be due to two fundamental aspects. Firstly, students of double degrees tend to be more studious and have better marks, since their cut-off mark for their admission is higher (11.680 and 6.205 for the double Degrees of PME and CME, respectively, compared to 5.000 for the Degree of ME) $[22,23]$. On the other hand, double-degree students are in a higher academic course (the participants were fifth-year students and third-year students from the double and single degrees, respectively) and are more mature; thus, they care more about their marks $[24,25]$. Nevertheless, it is curious to note that, although online teaching requires a greater dedication of the students to reach knowledge, both singleand double-degree students improve their marks in online experiences as it can been in Tables S1-S3.

Finally, women tended to have better marks in practical sessions than men, although without significant differences. This trend is surprising if we take into account that the number of women has been significantly lower than men in engineering careers throughout history [26]. Therefore, these results demonstrate the equal capacity of women and men to study technical careers. 


\subsection{Satisfaction Surveys}

Figure 4 shows the results of the satisfaction surveys carried out by the students after the study, evaluating how the incorporation of virtual tools has affected their perception of the subject. As can be seen, single-degree students seem to be more satisfied with the activity than double-degree students. This could be due to the age of the students, with the older ones (double-degree) having a more pessimistic profile, especially if the majority are male students [24]. These students are in their final year, where they value face-to-face activities much more due to their imminent entry into the world of work. Thus, the use of substitute virtual tools is less welcome among them, since they are concerned about not achieving all the necessary skills through online teaching. However, no significant differences were found between the different students.

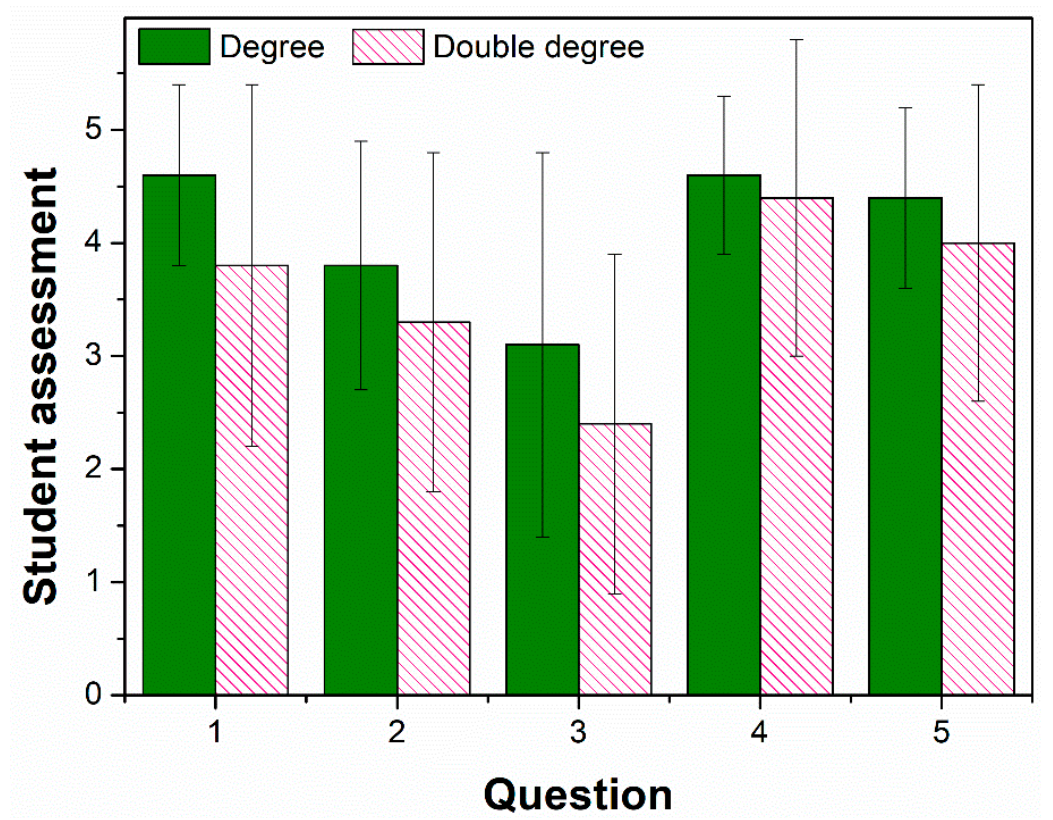

Figure 4. Satisfaction survey results.

Among the most interesting results, a low score was found in Question 3 (Online activities could replace face-to-face practical lectures). This means that most students preferred face-to-face practical lectures over online lectures, since internships in virtual environments do not provide hands-on experience in individual techniques or training in the use of individual equipment. Furthermore, they do not allow the analysis and interpretation of incorrect or unusual data [27]. The answers given by the students in the satisfaction survey revealed that they do not think that online activities could replace face-to-face ones. Therefore, they do not believe that this type of methodology can serve to strengthen the concepts at stake in the subject, an aspect that could lead to a loss of motivation and involvement due to this type of methodology. In fact, what was most relevant is the low score given to the question about "replace face-to-face lectures," even though the marks obtained were better with the alternative teachings. Therefore, they could be used as complement to, but not a substitute for, face-to-face practical lectures. Nevertheless, it is necessary to increase the quality of these virtual lectures in order to improve the effectiveness of their use.

\section{Conclusions}

The didactic principles followed to carry out the study were mainly: (i) Collaborative learning (mainly in face-to-face lectures), allowing students to interact with each other and thus allowing them to learn from each other, following the work of Marí Ytarte; and (ii) the search for motivation from the active participation of students through the use of new methodologies, following the trend of the studies of Roth. 
In this sense, the main limitation of this study was to carry out each different methodology with the same number of students and the same organization in order to proceed with a better comparison between the alternatives. Furthermore, another possible limitation was related to carrying out the virtual classes with more crowded groups, because it could be more difficult to coordinate.

Therefore, as a general conclusion, teaching concepts can be strengthened while exercising some of the essential specific skills in students. Nevertheless, virtual tools cannot yet replace face-to-face practical lectures, as determined by the satisfaction surveys; although the students' marks were not affected or even the marks obtained were better with the alternative methodologies. In fact, the necessary technology is not available to simulate the face-to-face experience in a real manner. In this way, students continue to prefer face-to-face practices, in all those who are more involved in the learning process (double-degree students are more dissatisfied than single-degree ones), as they believe that these improve their training. Moreover, the use of these tools for the development of complementary activities can be very useful to improve student performance.

Future research directions will be related to the implementation of a more complex and complete work, grouping colleagues from different areas (from the sciences and engineering and socio-sanitary fields) to conduct this study in a more general way to establish comparisons and to obtain better and more grounded conclusions.

Supplementary Materials: The following are available online at https:/ / www.mdpi.com/article / 10.3390/knowledge1010008/s1, Table S1: marks obtained for face-to-face lectures by each student. Table S2: marks obtained for educational videos by each student. Table S3: marks obtained for virtual lab by each student.

Author Contributions: Conceptualization, V.P.-P., M.J.-R., and A.R.; methodology, V.P.-P. and A.R.; software, M.J.-R. and A.R.; validation, V.P.-P.; formal analysis, V.P.-P., M.J.-R., and A.R.; investigation, V.P.-P., M.J.-R. and A.R.; resources, V.P.-P. and A.R.; data curation, M.J.-R.; writing—original draft preparation, M.J.-R.; writing—review and editing, V.P.-P. and A.R.; visualization, V.P.-P., M.J.-R. and A.R.; supervision, A.R.; project administration, V.P.-P.; funding acquisition, V.P.-P. and A.R. All authors have read and agreed to the published version of the manuscript.

Funding: This research was funded by Universidad de Sevilla (Ayuda 1.2.3, Convocatoria de Apoyo a la Coordinación e Innovación Docente, project number 24019).

Institutional Review Board Statement: Not applicable.

Informed Consent Statement: Not applicable.

Data Availability Statement: The data presented in this study are available on request from the corresponding author.

Acknowledgments: The authors acknowledge the post-doctoral grant of V. Perez-Puyana provided by Junta de Andalucía and Universidad de Sevilla (PAIDI-DOCTOR) and the pre-doctoral grant of M. Jiménez-Rosado provided by Ministerio de Educación y Formación Profesional (FPU2017/01718).

Conflicts of Interest: The authors declare no conflict of interest.

\section{References}

1. Comisión Europea, Tipos de Instituciones de Educación Superior, 2020. Available online: https:/ / eacea.ec.europa.eu/national-policies/ eurydice/content/types-higher-education-institutions-79_es\#: \{\}:text=Enlosdatosactualesdel,depostgrado(MásteryDoctorado) (accessed on 20 May 2021).

2. Murphy, M.P.A. COVID-19 and emergency eLearning: Consequences of the securitization of higher education for post-pandemic pedagogy. Contemp. Secur. Policy 2020, 41, 492-505. [CrossRef]

3. Kardong-Edgren, S.; Farra, S.L.; Alinier, G.; Young, H.M. A Call to Unify Definitions of Virtual Reality. Clin. Simul. Nurs. 2019, 31, 28-34. [CrossRef]

4. Escartín, E.R. La realidad virtual, una tecnología educativa a nuestro alcance. Pixel-Bit. Rev. Medios Educ. 2000, 15, 5-21.

5. Mendoza, L.I.U. Uso de la realidad virtual en la eduación del futuro en centros educativos del Ecuador. J. Sci. Res. Rev. Cienc. Investig. 2016, 1, 26-30. 
6. Díaz, I.A.; Rodríguez, J.M.R.; García, A.M.R. La tecnología móvil de Realidad Virtual en educación: Una revisión del estado de la literatura científica en España. EDMETIC 2018, 7, 256. [CrossRef]

7. J García Martín, S.G.M. Uso de herramientas digitales para la docencia en España durante la pandemia COVID-19. Rev. Española Educ. Comp. 2021, 38, 151-173. [CrossRef]

8. Fernández, P.G. Aprendizaje Autónomo Utilizando Vídeos Docentes. Rev. Iberoam. Tecnol. Aprendiz. 2011, 6, 65-69.

9. Huang, C. Virtual Labs: E-Learning for Tomorrow. PLoS Biol. 2004, 2, e157. [CrossRef] [PubMed]

10. Del, P.M.; Jiménez, M.; Atienza, A.C.; Abellán, M.V.; Martínez, P.A. Laboratorios Virtuales Sobre Prevención de Riesgos Laborales, 2018. Available online: http:/ / www.uco.es/RiesgosLaborales/ (accessed on 20 May 2021).

11. Universidad de Alcalá, Biomodel, 2011. Available online: http:/ / biomodel.uah.es/lab/inicio.htm (accessed on 20 May 2021).

12. Powell, A.; Watson, J.; Staley, P.; Horn, M.; Fetzer, L.; Hibbard, L.; Oglesby, J.; Verma, S. Blending Learning: The Evolution of Online and Face-to-Face Education from 2008-2015; iNACOL: Vienna, VA, USA, 2015. Available online: https://eric.ed.gov/?id=ED560788 (accessed on 19 October 2021).

13. Watson, J. Blended Learning: The Convergence of Online and Face-to-Face Education. Promising Practices in Online Learning; iNACOL: Vienna, VA, USA, 2008.

14. Cannon, J.P.; Lohtia, R.; Paulich, B.J. Blended Learning in Principles of Marketing: The Effects of Student Differences on Student Performance. J. Mark. Educ. 2021, 027347532110583. [CrossRef]

15. Ganiyu, B. Colleges of education science student engagement in Emergency Remote Teaching amidst COVID-19 in Nigeria. J. Pendidik. Biol. Indones. 2021, 7, 258-266. [CrossRef]

16. Bartley, S.J.; Golek, J.H. Evaluating the cost effectiveness of online and face-to-face instruction. Educ. Technol. Soc. 2014, 7, 167-175.

17. Perez-Puyana, V.; Jiménez-Rosado, M.; Romero, A.; Rubio-Valle, J.F. Procesado de Andamios (Scaffolds) vía Hidrogeles con Aplicación en Ingeniería Tisular; Universidad de Sevilla: Sevilla, Spain, 2019; ISBN 978-84-17337-61-2.

18. Ramos, M.; Perez-Puyana, V.; Jiménez-Rosado, M.; Romero, A. Fabricación de Matrices de Nanofibras Memdiante Electrohilado; Universidad de Sevilla: Sevilla, Spain, 2019; ISBN 978-84-17337-60-5.

19. Perez-Puyana, V.; Romero, A.; Felix, M.; Jiménez-Rosado, M. Desarrollo de Hidrogeles Biopoliméricos para la Regeneración de Tejidos Blandos; Universidad de Sevilla: Sevilla, Spain, 2020. Available online: https:/ / ochoymediolibrosdecine.es/productos/libro/ desarrollo-de-hidrogeles-biopolimericos-para-la-regeneracion-de-tejidos-blandos/ (accessed on 19 October 2021).

20. Perez-Puyana, V.; Romero, A.; Felix, M.; Jiménez-Rosado, M. Esferas de Liberación Controlada con Aplicación en la Industria Farmacéutica; Universidad de Sevilla, Sevilla, Spain, 2020. Available online: https:/ /tv.us.es/esferas-de-liberacion-controladacon-aplicacion-en-la-industria-farmaceutica/ (accessed on 19 October 2021).

21. Puyana, V.M.P.; Rosado, M.J.; García, A.R. En busca del biomaterial perdido, Portal Real. Extendida La Univ. Sevilla 2021. [CrossRef]

22. Universidad de Sevilla, Notas de corte de Grado 2020-21, 2020. Available online: https:/ / estudiantes.us.es/sites/default/files / ficheros/file/informacion/PLAZAS\%2BNOTASDECORTE_2020-21.pdf? (accessed on 17 September 2021).

23. El País, Notas de corte 2021, (2021).

24. Rubin, M.; Scevak, J.; Southgate, E.; Macqueen, S.; Williams, P.; Douglas, H. Older women, deeper learning, and greater satisfaction at university: Age and gender predict university students' learning approach and degree satisfaction. J. Divers. High. Educ. 2018, 11, 82-96. [CrossRef]

25. Richardson, J.T.E. Mature students in higher education: II. An investigation of approaches to studying and academic performance. Stud. High. Educ. 1995, 20, 5-17. [CrossRef]

26. Bebbington, D. Women in Science, Engineering and Technology: A Review of The Issues. High. Educ. Q. 2002, 56, 360-375. [CrossRef]

27. Gamage, K.A.A.; Wijesuriya, D.I.; Ekanayake, S.Y.; Rennie, A.E.W.; Lambert, C.G.; Gunawardhana, N. Online Delivery of Teaching and Laboratory Practices: Continuity of University Programmes during COVID-19 Pandemic. Educ. Sci. 2020, 10, 291. [CrossRef] 